\title{
Ginzburg na oficina do historiador da educação: algumas considerações metodológicas
}

Ginzburg in the education historian's workshop: some methodological considerations

Ginzburg en el taller del historiador de la educación: algunas consideraciones metodológicas

Thiago Borges de Aguiar

Universidade Metodista de Piracicaba (Brasil)

https://orcid.org/0000-0002-7294-1200

http://lattes.cnpq.br/4157841228850122

tbaguiar@outlook.com.br

Paula Leonardi

Universidade do Estado do Rio de Janeiro (Brasil)

https://orcid.org/0000-0003-4046-9703

http://lattes.cnpq.br/6930629041565848

leonardi.paula@gmail.com

Fernando Antonio Peres

Rede Municipal de Ensino de São Paulo (Brasil)

http://orcid.org/0000-0001-6171-1840

http://lattes.cnpq.br/3172710350433799

peres.f.a@uol.com.br

\section{Resumo}

Neste artigo, refletimos sobre os procedimentos metodológicos empregados pelo historiador italiano Carlo Ginzburg em sua obra, apontando para como esses procedimentos podem ser usados em nossas pesquisas na área de história da educação. Partimos de dois artigos que trataram do paradigma indiciário no campo da história da educação a partir das categorias de distância e estranhamento e das relações entre verdade e linguagem. Propomos pensarmos nossas pesquisas a partir da densidade literária, diálogo interdisciplinar e tratamento das fontes. Compreendemos que a pesquisa em história da educação inserida em um Paradigma Indiciário implica erudição, preservação da dúvida, diálogo com o olhar de outras áreas para nossos objetos de investigação, compreensão do lugar do acaso na pesquisa e assunção de uma postura de exílio em relação às fontes (e a nós mesmos) para que nosso método de leitura indiciária possa preservar o caráter de indecifrabilidade presente em toda produção cultural humana.

Palavras-chave: Paradigma indiciário. Método indiciário. Metodologia científica. História da Educação. Carlo Ginzburg. 


\begin{abstract}
In this article, we reflect on the methodological procedures employed by the Italian historian Carlo Ginzburg in his work, pointing out how these procedures can be used in our research in the area of education history. We started from two articles that dealt with the evidential paradigm in the field of the history of education from the categories of distance and strangeness and the relationships between truth and language. We propose to think our research based on literary density, interdisciplinary dialogue, and treatment of sources. We understand that research in the history of education inserted in an Evidential Paradigm implies erudition, preservation of doubt, dialogue with the reading of other areas to our objects of investigation, understanding the role of chance in research and assuming a posture of exile in relation to the sources (and ourselves) so that our method of reading evidences can preserve the character of undecipherability present in all human cultural production.
\end{abstract}

Key words: Evidential paradigm. Evidential method. Scientific methodology. History of Education. Carlo Ginzburg.

\title{
Resumen
}

En este artículo, reflexionamos sobre los procedimientos metodológicos empleados por el historiador italiano Carlo Ginzburg en su producción, señalando cómo estos procedimientos pueden utilizarse en nuestra investigación en el área de la historia de la educación. Comenzamos con dos artículos que trataban el paradigma evidencial en el campo de la historia de la educación desde las categorías de distancia y extrañeza y las relaciones entre la verdad y el lenguaje. Proponemos pensar nuestra investigación basada en la densidad literaria, el diálogo interdisciplinario y el tratamiento de las fuentes. Comprendimos que la investigación en la historia de la educación insertada en un paradigma indígena implica erudición, preservación de la duda, diálogo con la búsqueda de otras áreas para nuestros objetos de investigación, comprensión del lugar del azar en la investigación y asumir una postura de exilio en relación con las fuentes (y nosotros mismos) para que nuestro método de lectura de evidencias pueda preservar el carácter de indescifrabilidad presente en toda la producción cultural humana.

Palabras clave: Paradigma evidencial. Método evidencial. Metodología científica. Historia de la Educación. Carlo Ginzburg. 


\section{Introdução}

Este artigo tem como objetivo refletir sobre os procedimentos metodológicos empregados pelo historiador italiano Carlo Ginzburg (nasc. 1939) em sua produção historiográfica, pensando nas possibilidades que esses procedimentos oferecem para a pesquisa na área de História da Educação ${ }^{1}$.

A obra do historiador italiano compreende um pouco mais de meio século, com dezenas de publicações, inaugurada com "Stregoneria e pietá popolare", que veio à luz nos Annali della Scuola Normale Superiore di Pisa (1961). Sua produção publicada no Brasil compreende obras monográficas, em especial Andarilhos do bem (original de 1966), O queijo e os vermes (de 1976), História Noturna (de 1989) entre outras monografias menos conhecidas e numerosos artigos, ensaios e conferências, muitos deles publicados em periódicos e posteriormente reunidos em coletâneas.

Nesses textos, além da análise refinada dos objetos de estudo escolhidos para a pesquisa histórica, percebe-se uma preocupação recorrente do autor em expor e discutir princípios norteadores da prática historiográfica, contribuindo assim para o aperfeiçoamento do ofício do historiador.

As publicações de Ginzburg em língua portuguesa (no Brasil) iniciam-se em 1987, com a tradução de $O$ queijo $e$ os vermes. Nos anos seguintes, foram publicados $O s$ andarilhos do bem (1988), Mitos, emblemas, sinais (1989) e Indagações sobre Piero (também em 1989). A micro-história e outros ensaios e História noturna vieram a público em 1991. Na década seguinte, são publicados Olhos de madeira (2001), Relações de força (2002), Nenhuma ilha é uma ilha (2004), O fio e os rastros (2007b), uma nova edição de Investigando Piero (2010) e Medo, reverência, terror (2014).

Portanto, um autor bastante traduzido e publicado no Brasil nos últimos vinte e cinco anos. Apesar disso, Ginzburg ainda é pouco citado (e referenciado) na pesquisa histórica no Brasil. No campo específico da história da educação, a situação não era muito diferente dez anos atrás (cf. LEONARDI; AGUIAR, 2010) e continua assim nos dias de hoje. Quando olhamos para os textos desse autor que circulam nas pesquisas, percebemos certo desconhecimento de sua obra, mesmo se considerarmos apenas o material traduzido. Mesmo entre aqueles que citam o autor, parte significativa referência, basicamente, dois de seus textos, como veremos mais adiante.

É claro que nosso olhar para o autor está marcado pelo modo como ele contribuiu para as pesquisas que realizamos (cf. LEONARDI, 2010; AGUIAR, 2012; PERES, 2012) e pelo modo como demos sequência a elas. No entanto, compreendemos, inclusive em respeito ao próprio modo como o autor apresenta suas ideias, que as propostas metodológicas que Ginzburg nos oferece para a pesquisa na área de história da educação não podem ser tomadas como suficientes, exclusivas ou acima de qualquer crítica possível. E, nesse sentido, fazemos referência à crítica levantada por Pires (2013) a respeito do caráter de "método insuspeito" que as propostas do historiador italiano tendem a assumir em diversos momentos.

Além disso, não trataremos, neste texto, da discussão sobre a micro-história como um movimento de historiadores italianos e as vinculações de Ginzburg com esse "conjunto de proposições e questionamentos sobre os métodos e os procedimentos da história social" (Espada Lima, 2006, p. 16). Como essa relação é bastante explorada nos trabalhos de Ronaldo Vainfas (2002) e de Henrique Espada Lima (2006), bem como nas discussões de Ginzburg (2007b, p. 249 e seguintes) e de Levi (2017), a eles remeteremos o leitor.

Nossa perspectiva é outra, pois procuramos registrar o esforço de nos apropriarmos da obra de Carlo Ginzburg, empregando-a como importante ferramenta metodológica quando adentramos na oficina do historiador da educação. Para nos empenharmos nesta reflexão

\footnotetext{
${ }^{1}$ Nós, os autores deste artigo, agradecemos aos membros do Grupo de Estudos de História da Educação e Religião (GEHER), em particular, pelo tempo que passamos juntos lendo e discutindo uma parte significativa do trabalho de Carlo Ginzburg. De certa forma, este artigo homenageia e registra os vários anos de leitura sistemática da obra do autor, bem como suas repercussões posteriores em nosso trabalho como estudiosos.
} 
metodológica, partimos de uma de nossas primeiras sistematizações da obra do autor e de um diálogo com um artigo recém publicado que busca também fazer tal sistematização. $\mathrm{Na}$ sequência, na esteira do que estes textos fizeram, avançamos em relação a uma leitura mais abrangente de sua obra, propondo, para o historiador da educação que se propuser a trabalhar tomando Ginzburg como uma referência teórico-metodológica, um guia por sua vasta obra publicada em português. Para tanto, olhamos para as contribuições do historiador italiano a partir de três eixos: a densidade literária, o diálogo interdisciplinar e o tratamento documental.

\section{Ginzburg entre historiadores da educação brasileiros}

Pensar nas contribuições do historiador italiano para as pesquisas na história da educação passa por buscar referências a discussões teórico-metodológicas em sua obra. Em alguns momentos, ele se propôs a fazer tais reflexões, mas é fundamental observarmos não apenas como ele explica seus procedimentos como também como ele os realiza. Nesse sentido, é necessário enveredar por parte significativa de seus escritos, indo além de um conjunto específico de textos de reflexão teórico-metodológica.

Na busca por artigos que tenham feito tal mapeamento na área da história da educação, encontramos apenas dois. No primeiro, Leonardi e Aguiar (2010) propuseram-se a fazer um levantamento das publicações em história da educação que fizeram referência ao historiador italiano em quatro revistas da área, desde seu início até aquele momento. Encontraram 11 artigos. Nesse levantamento constataram que, até aquele momento, o mais comum era a ocorrência de trabalhos que utilizavam os termos "indícios" ou "vestígios" em suas pesquisas históricas ou tomavam o paradigma indiciário como uma "inspiração geral e difusa" para o desenvolvimento da investigação. Poucos autores, no que diz respeito ao papel que o historiador italiano possuía para fundamentar teórico-metodologicamente aquele trabalho, fizeram mais do que uma descrição, em linhas gerais, de uma leitura indiciária de suas fontes. Também ficou marcado que, da vasta obra do autor traduzida para o português, são citados, prioritariamente, o livro O queijo e os vermes e o livro Mitos, Emblemas e Sinais (deste, especificamente, o ensaio mais famoso do autor, Sinais, raízes de um paradigma indiciário).

É compreensível que estes sejam os textos mais citados, visto que, o primeiro é o livro de maior circulação mundial do autor, aquele pelo qual ele ficou conhecido, e, no qual, a leitura indiciária que ele propõe é longamente descrita no prefácio e amplamente desenvolvida no decorrer das páginas seguintes. Já o ensaio Sinais é o principal esforço do autor de sistematizar o que ele chamou de Paradigma Indiciário e o modo como suas investigações se inserem dentro desse paradigma. No entanto, caso Ginzburg seja tomado como principal subsídio teórico-metodológico para o desenvolvimento de uma pesquisa em história da educação, a leitura destes dois únicos textos pode restringir a compreensão do que ele propôs como trabalho historiográfico, especialmente considerando que o primeiro foi publicado, pela primeira vez, em 1976 e o segundo em 1979. De lá para cá, o autor, que continua vivo e profissionalmente ativo até hoje, publicou uma vasta quantidade textos. É o que o referido artigo já apontava há dez anos:

Ao negligenciar a continuidade de seu pensamento a respeito do paradigma indiciário contido em Nenhuma ilha o leitor acaba por não perceber a ênfase que o próprio Ginzburg dá para a escrita da história, para a narrativa. O paradigma indiciário que perpassa a obra de Ginzburg tem por característica um observador que, a partir de dados aparentemente negligenciáveis, dispõem esses dados para fazer emergir uma narrativa. Esses três elementos (observador, dados, narrativa) são indissociáveis. Entretanto, há ainda outro elemento para o qual daremos 
mais ênfase neste texto: trata-se da postura do observador diante dos indícios, a postura de distanciamento e estranhamento. (LEONARDI; AGUIAR, 2010, p.115, grifos dos autores).

Os autores fazem referência ao fato que Ginzburg comenta, no prefácio do livro Nenhuma ilha é uma ilha, o modo como o ensaio Sinais se insere em sua produção historiográfica. E apontam, na sequência do artigo, as categorias de distanciamento e estranhamento como fundamentais na compreensão do paradigma indiciário, compreendendoos num exercício de escrita historiográfica de alternância entre micro e macro, entre o geral e o particular, levando em consideração, em especial, os textos escritos no livro Olhos de madeira. Afirmam os autores que "a distância se constrói no reconhecimento da existência do outro, no estranhamento de nossa própria existência e na manutenção da tensão entre o ponto de vista subjetivo e verdades objetivas." (LEONARDI; AGUIAR, 2010, p.120).

Com a ênfase nos termos distância e estranhamento para a compreensão do paradigma indiciário (para além do termo indícios), os autores abriram espaço para uma ampliação da compreensão de como tomar as ideias do historiador italiano como referência para subsidiar teóricometodologicamente pesquisas na área de história da educação. Considerando que ele não tenha tratado especificamente de educação, os autores concluem seu texto propondo questões especificamente para a área. Três são as questões principais: (1) considerar o caráter necessariamente interdisciplinar para o objeto "educação"; (2) tomar um olhar "oblíquo" para a história da educação, buscando evitar uma leitura que considere as práticas educativas atuais como a resultado necessário do desenvolvimento das práticas de períodos históricos anteriores e (3) problematizar a possibilidade de um olhar indiciário para fenômenos cujas fontes nos permitem apenas referências indiretas, como compreender o olhar de um educando a partir de fontes produzidas pelo educador.

Nos últimos dez anos, o historiador italiano, continua a ser referenciado na história da educação em termos semelhantes aos que foram apontados em 2010. Com uma louvável exceção. No segundo artigo encontrado, Paziani e Perinelli (2018) propõem-se a apresentar Carlo Ginzburg para o público acadêmico das áreas de história e história da educação, com vistas a "promover reflexões sobre o paradigma indiciário", especialmente na relação com "os domínios da linguagem e a Análise do Discurso de Pêcheux". Os autores buscam inseri-lo no campo da História da Educação como alguém que não é "pós-moderno", que possui um importante diálogo com pensadores marxistas e que deve não deve ser colocado entre os historiadores da (Nova) História Cultural em função da crítica que Dermeval Saviani fez, no final dos anos 90, ao impacto dessa corrente historiográfica nas pesquisas em História da Educação.

Nas considerações finais, eles chamam a atenção ao desconhecimento da obra de Ginzburg e passam a afirmar, claramente, que este historiador não pertence à (Nova) História Cultural e nem é um autor pós-moderno:

Apesar de ser considerado um nome fundamental da Micro-História (VAINFAS, 2002; LIMA, 2006) e estabelecer mediações teóricas e metodológicas com a produção historiográfica dos Annales, não se pode rotulá-lo categoricamente de pertencer a "(Nova?) História Cultural" (e tampouco de intelectual "pós-moderno"): trata-se de um reducionismo axiológico, que não apenas fragmenta o conhecimento histórico, como encerra-o numa falsa autonomia da cultura. (PAZIANI; PERINELLI, 2018, p. 330).

Posteriormente, os autores buscam mostrar que há marcantes ("notórias", nos termos dos autores) referências de dois pesquisadores marxistas no pensamento de Ginzburg: "Se fizermos uma analogia com a seara marxista, Ginzburg estaria num mesmo espectro intelectivo 
de Mikhail Bakhtin e Walter Benjamin.” (PAZIANI; PERINELLI, 2018, p. 330). Por fim, concluem, a partir das "pistas" do texto de Saviani que:

parece oportuno considerar as contribuições proporcionadas pela obra de Carlo Ginzburg, especialmente no que tange as reflexões teóricometodológicas contidas no "paradigma indiciário", tendo em vista a problematização diferente que apresenta da relação entre linguagem, história e verdade. (PAZIANI; PERINELLI, 2018, p. 330).

Esta síntese mais geral é subsidiada, ao longo do texto, pelas marcas políticas da formação de Ginzburg (especialmente em relação a seu pai e sua mãe) e pelo modo como ele se relaciona com a linguagem. Na aproximação com a Análise do Discurso de Pêcheux, há várias semelhanças, mas há uma diferença importante: a relação com a verdade e o acesso a ela. E este é um elemento fundamental para marcar o lugar de Ginzburg como alguém que não entra na crítica de Saviani ao pensamento pós-moderno na pesquisa em história da educação.

Ao longo do artigo, Paziani e Perinelli fazem uma abrangente discussão das relações entre a formação intelectual do historiador italiano e sua obra, buscando "paralelos" que possam melhor compreender sua relação com a pesquisa, em especial na área da linguagem. Os autores dedicam alguns parágrafos destacar elementos da vida de Leone e Natalia Ginzburg, em especial o trabalho de ambos com a literatura, bem como seu ativismo político (Natalia, inclusive, foi deputada pelo partido comunista nos anos de 1983 a 1991), seguindo-se um longo trecho no qual três espaços universitários/de pesquisa (Universidades de Pisa e Bolonha e Instituto Aby Warburg) se tornarão referências na formação do historiador italiano nos anos 1950 e 1960.

Os autores destacaram, também, as influências do debate sobre a obra de Croce e a de Gramsci, apontando que Ginzburg não se filiou ao primeiro e, apesar de se afirmar "muito ignorante" em relação às obras de Marx, o historiador italiano recebeu a influência marxiana via Hobsbawn e Gramsci e do campo da epistemologia (especificamente citando autores da hermenêutica) como Ricouer e Gadamer. Seguem, então, para uma lista de influências na formação do jovem Ginzburg: (1) a filologia e a "leitura lenta e detalhada", especialmente a partir de Cantimori, Erich Auerbach, Leo Spitzer e Gianfranco Contini, (2) Marc Bloch e o enfrentamento de "temas marginais" para pensar sobre "problemas mais amplos", a "prática da alteridade no enfrentamento dos discursos constituintes das fontes de pesquisa" e a "presença da dúvida e da busca incessante pela verdade"; (3) o historiador italiano Frederico Chabod e do período no Instituto Warburg para pensar no "estudo do particular"; (4) "linguistas como Fernand Saussure, Roman Jakobson e Mikhail Bakhtin" e (5) Freud, em especial da Psicopatologia da Vida Cotidiana (PAZIANI; PERINELLI, 2018, p. 320 e seguintes)

Sem desconsiderar o escopo específico do artigo dos autores, poderíamos acrescentar aqui a menção que Ginzburg faz à obra Minima Moralia, de Adorno (GINZBURG, 1989, p. 10), bem como, mais tardiamente em sua obra, a importância do período em que trabalhou na UCLA para a compreensão que o autor atribuiu à distância e ao exílio (GINZBURG, 2010, p. 11).

Paziani e Perinelli tratam, então, de características do Paradigma Indiciário, em especial a partir de uma aproximação com a Análise do Discurso:

um método de análise discursiva na qual o historiador, por exemplo, deve dedicar-se a tarefa de ler e interpretar intensivamente as fontes coletadas, vendo estas enquanto "discursos" que o auxiliem na compreensão das intenções subjetivas e dos expedientes narrativos presentes em um determinado "texto" (ou conjunto de "textos"), tanto em sua dimensão discursiva propriamente dita, quanto na 
dimensão extradiscursiva (a não-transparência da linguagem). (PAZIANI; PERINELLI, 2018, p. 325).

$\mathrm{Na}$ sequência, tratam densamente sobre a questão da verdade e da prova histórica, apontando diferenças entre a Análise do Discurso e o Paradigma indiciário justamente na questão da compreensão do conhecimento verdadeiro, que

na escrita histórica passa necessariamente pelo valor heurístico atribuído às narrativas históricas e ficcionais e os modos pelos quais elas, numa perspectiva dialética, possibilitam uma gama variada de acessos ao "Outro" no tempo e ao que chamamos de "passado". (PAZIANI; PERINELLI, 2018, p. 329).

Tanto o artigo de 2010 quanto o de 2018 apresentam, dentro de seus escopos, uma leitura abrangente da obra de Ginzburg, especialmente por buscar compreender os modos como o autor é ainda pouco conhecido campo da história da educação (visto ser citado de formas muito ligeiras), a compreensão da distância e do estranhamento como categorias fundamentais para a compreensão do paradigma indiciário e o estatuto da prova e da verdade na produção histórica, em especial no diálogo com autores do campo da linguagem.

Seguindo a partir do que os autores já apontaram, buscaremos, neste momento, voltar nosso olhar não apenas para o modo como Ginzburg explicita suas questões nos textos de caráter reflexivo sobre seu ferramental teórico-metodológico, mas também nos demais textos nos quais esse ferramental é posto em uso. Esse exercício levou-nos a sistematizar as contribuições de Ginzburg em três tópicos: densidade literária, ou erudição, diálogo interdisciplinar e tratamento documental.

\section{Densidade literária}

Os textos de Ginzburg trazem ao leitor uma ampla variedade de autores e de suas obras, muitos dos quais pouco circulam entre os historiadores brasileiros. Empregando uma bibliografia em língua italiana, inglesa, francesa e alemã, assim como textos nessas línguas, bem como em latim e grego, seus escritos transformam-se num exercício de vasculhar um mundo desconhecido. Como afirmou Peter Burke (1990, p. 108), Ginzburg é um "leitor voraz", que "não esqueceu sua educação clássica e filosófica" 2 .

Assim, poderíamos até afirmar que Ginzburg fosse um "erudito", se tal expressão não tivesse, na profissão de historiador, um sentido tão peculiar - de especialista, versado na análise crítica dos documentos, desde pelo menos os anos finais do século XIX.

No entanto, sua escrita no formato de ensaio favorece uma leitura despreocupada com essas referências. Não é incomum observarmos pessoas que leem seus ensaios quase como "ficção literária". Mas é na análise de suas notas (de rodapé ou de fim de página) que encontramos referências que apontam para sua caracterização como um leitor voraz e variado, sempre disposto a efetuar uma revisão bibliográfica vasta e minuciosa ${ }^{3}$.

A título de exemplo ${ }^{4}$, podemos lembrar alguns autores da Antiguidade grega e latina, e dos primórdios da era cristã, que são visitados pela narrativa de Ginzburg: Agostinho (354-430); Ambrósio (c. 340-397); Aristóteles (384 - 322 a.C.); Boécio (c. 480 - c. 525);

\footnotetext{
${ }^{2}$ No original: "It is clear that Ginzburg is a voracious reader, that he has not forgotten his classical and philosophical education, and that he is at least as concerned with intellectual currents in the twentieth century as in the sixteenth".

${ }^{3}$ Esta preocupação evidencia-se desde seu primeiro ensaio, de 1961, quando o autor tinha 22 anos de idade!

${ }^{4}$ Nas listas que apresentamos na sequência do texto, não temos a pretensão de ser exaustivas, mas tomamos o cuidado de tratá-las de forma abrangente.
} 
Cícero (106 - 43 a.C.); Diógenes da Selêucia (c. 230 - c. 140 a.C.); Dioniso de Halicarnasso (séc. I a.C.); Eusébio de Cesareia (c. 265 - 339); Gaio (c. 130 - 180); Heródoto (c. 485 420 a.C.); Hipócrates (c. 460 - c. 377 a.C.); Jerônimo (c. 347 - 420); Lactâncio (c. 240 - c. 320); Luciano de Samosata (c. 125 - c. 181); Macróbio (c. 370 - c. 430); Marco Aurélio (121 - 180); Ovídio (43 a.C - c. 18 d.C); Platão (c. 428 - 348 a.C.); Plutarco (c. 50 - 125); Políbio (c. 203 - 120 a.C.); Quintiliano (35 - 95); Salústio Crispo (86 - 34 a.C.); Sexto Empírico (séc. II - III d.C.); Sócrates (c. 470 - 399 a.C.); Tácito (c. 55 - c. 120); Tertuliano (c. 155 - c. 222); Tito Lívio (59 a.C. - 17 d.C.); Tucídides (c. 465 - 395 a.C.); Ulpiano (150 - 223); Vitrúvio Pólion (séc. I a.C.); Xenofonte (c. 430 - 355 a.C.).

Da mesma forma, Ginzburg utiliza-se, em seus estudos nos domínios da história, dos autores de obras literárias: Balzac; Boccaccio; Cervantes; Conan Doyle; Dante; Dostoievski; Flaubert; Goethe; Heine; Homero; John Donne; Proust; Robert Louis Stevenson; Stendhal; Swift; Tolstoi; Victor Hugo.

Grandes pensadores também são visitados e analisados por Ginzburg: Adorno; Benjamin; Descartes; Diderot; Erasmo; Freud; Gramsci; Hegel; Hobbes; Hume; Leibnitz; Lévi-Strauss; Lutero; Maquiavel; Marx; Montaigne; Nietzsche; Spinoza; Thomas More; Tocqueville; Voltaire.

Da mesma forma, os historiadores são sempre muito lembrados e amplamente citados, em especial Michelet, Marc Bloch e Lucien Febvre.

Quanto às fontes primárias, Ginzburg emprega os processos inquisitoriais, obras literárias e obras de arte para elaborar suas reflexões históricas. Como exemplo, podemos citar $O$ s andarilhos do bem, $O$ queijo e os vermes e História noturna como textos que empregam à exaustão os processos inquisitoriais. Voltaire, Balzac e Stendhal aparecem nos artigos que compõem $O$ fio e os rastros. E, para além da literatura, as obras plásticas de Piero della Francesca são exploradas no Investigando Piero, bem como Picasso apareceu em ensaios de Mitos, Emblemas e Sinais e de Medo, Reverência e Terror.

A densidade literária, assim, apresenta-se como uma importante recomendação aos historiadores de ofício: uma pesquisa histórica de qualidade pressupõe um conhecimento de textos clássicos da história da humanidade, emprego de fontes primárias e contato constante com a produção historiográfica sobre o assunto a ser investigado. Sempre convém lembrar que não escrevemos história sozinhos, desvinculados de grandes pensadores e correntes de pensamento e sem a busca incessante por documentos que possam comprovar nossas indagações históricas e narrativas. $\mathrm{O}$ da poco fare più que se associa a Ginzubrg, numa leitura equivocada, nos levaria a pensar que bastam poucos materiais para se produzir um trabalho histórico. Uma das principais lições que Ginzburg nos oferece é perceber que de poucas fontes e referências faz-se muito apenas com intensa pesquisa historiográfica e com a erudição que surge do conhecimento aprofundado sobre o tema. O itinerário percorrido pelo autor para produzir suas três principais obras monográficas - Os andarilhos do bem, O queijo e os vermes e História noturna - demonstram a afirmação acima.

A sólida ancoragem na pesquisa empírica, com a análise crítica das fontes primárias, é suficiente para afastar qualquer suspeita de que o autor esteja a praticar ficção literária em seus escritos.

Além disso, no âmbito do Paradigma Indiciário, entendemos essa densidade literária como um pressuposto para lidar com a decifração de uma realidade que é opaca a partir de "zonas privilegiadas - sinais, indícios - que permitem decifrá-la" (GINZBURG, 1987, p. 177). $\mathrm{O}$ autor compreende e valoriza a possibilidade de um conhecimento que busca a totalidade, mesmo tratando de elementos marginais, negligenciáveis. Na medida em que se afirme que é impossível o acesso direto a um (objeto de) conhecimento, destaca-se a sua existência e a existência de meios indiretos para acessá-lo. 
Esta relação entre um conhecimento que busca a totalidade e o acesso a ele por meio de sinais e indícios é perpassada pela erudição. Como lidar com a escassez de fontes sobre um objeto histórico? "Preenchendo" as lacunas com a compreensão adensada do entorno, construindo analogias e preservando o caráter da dúvida que essas analogias oferecem. Davis (1987), em sua investigação histórica sobre o caso de Martin Guerre, após descrever o levantamento de suas fontes, afirma: "O que aqui ofereço ao leitor é, em parte, uma invenção minha, mas uma invenção construída pela atenta escuta das vozes do passado.” (p. 21)

Ginzburg escreve um posfácio à edição italiana do livro de Davis e faz uma longa discussão sobre a relação entre ficção e verdade. Partindo da aproximação "pós-moderna" entre ficção e história, Ginzburg, nesse posfácio (2007b, p. 311 e seguintes), insere seu projeto de trabalho (e, portanto, o debate sobre paradigma indiciário) em uma reflexão sobre os conflitos oriundos do modo como ambas (ficção e história) representam a realidade. De certo modo, uma tensiona, provoca e realiza trocas com a outra, mas não se trata da mesma representação. É neste sentido que deve ser lida a obra de Ginzburg. Como o autor apresenta em nota aos seus "vinte anos de pesquisa", essa reflexão está presente nos livros Olhos de Madeira, Relações de Força, Nenhuma ilha é uma ilha e $O$ fio e os rastros.

Nesse sentido, podemos entender o método indiciário como o modo como Ginzburg propõe compreender uma relação entre rastros, vestígios, indícios, sinais selecionados de seu objeto de investigação pelo pesquisador e a narrativa que este elabora para dar sentido a essa seleção. A compreensão dessa relação exige uma reflexão sobre as tensões entre ficção e realidade.

Esta tensão é fundamental para compreender o termo "invenção" de Davis e o modo como "preenchemos" as lacunas da documentação com uma necessária densidade literária. Ginzburg começa o prefácio com o ensaio de Montaigne para fazer um recurso de analogia entre a fala do ensaísta francês e as escolhas que Natalie Zemon Davis fez dos termos para escrever seu livro. Trata-se de um elogio às afirmações parciais, com a presença de termos que expressam claramente a dúvida do historiador. Além disso, essa analogia é estabelecida com um texto que cita diretamente o mesmo caso que Davis estudou.

Esse procedimento de buscar analogias e associações entre textos que citam uns aos outros, entender sua circulação e o modo como um pode ter lido o outro é recurso comum nos ensaios de Ginzburg. Trata-se de buscar aproximações, conexões, ligações que podem ser diretas ou indiretas, podendo ser historicamente comprovadas ou apenas hipóteses (como ele fez no livro História Noturna - publicação que Ginzburg fez alguns anos depois da escrita deste posfácio).

Mais à frente, Ginzburg trata do termo "invenção", ampliando seu significado no debate da relação ficção-verdade:

O termo "invenção" (invention) é voluntariamente provocatório - mas, no fim das contas, desviante. A pesquisa (e a narração) de Davis não é centrada na contraposição entre "verdadeiro" e "inventado", mas na integração, sempre escrupulosamente assinalada, de "realidades" e "possibilidades". Decorre daí o pulular, em seu livro, de expressões como "talvez", "deviam", "pode-se presumir", "certamente" (que na linguagem historiográfica costuma significar "muito provavelmente") etc. (GINZBURG, 2007b, p. 315).

Trata-se de um destaque à correta contraposição apresentada pela pesquisa de Davis, não entre verdadeiro e inventado, mas entre realidade e possibilidade. O que Ginzburg traz, então, é a consideração que, diferente do juiz, a ausência de provas para o historiador exige uma investigação de "homens e mulheres do mesmo tempo e do mesmo lugar" (p. 316 citando Davis). O que o leva ao ponto central de seu argumento: “'Verdadeiro' e 'verossímil', 'provas' e 'possibilidades' se misturam, permanecendo 
embora rigorosamente distintos". (GINZBURG, 2007b, p. 316) Ou seja, a presença de provas e possibilidades faz parte do exercício historiográfico de preencher as lacunas do verdadeiro com o verossímil. Mas isso não implica na indistinção entre eles. O texto de Davis deixa claro o que é estabelecido por provas e o que é estabelecido por possibilidades. A dúvida está, portanto, presente e explícita, mas não apenas como questão por resolver, mas como questão resolvida por analogia.

No campo da pesquisa, implica entender que o paradigma indiciário não trata de buscar elementos pequenos para imaginar como completar o resto. Trata de lidar, sim, com a conjectura, aceitando-a como tal, lidar com a dúvida, aceitando-a como tal, implicar-se na pesquisa, explicitamente marcado como tal. É estar presente. Não é apresentar o conteúdo como se fosse uma certeza, mas com a gradação dos diferentes níveis de certeza que a pesquisa permitiu atingir marcados na escrita do texto acadêmico.

Ao final do posfácio, após longa discussão sobre as relações entre verdade e conhecimento histórico, Ginzburg conclui:

Termos como "ficção" ou "possibilidade" não devem induzir a erro. A questão da prova permanece mais que nunca no cerne da pesquisa histórica, mas seu estatuto é inevitavelmente modificado no momento em que são enfrentados temas diferentes em relação ao passado, com a ajuda da uma documentação que também é diferente. A tentativa feita por Natalie Zemon Davis de contornar as lacunas com uma documentação arquivística, contígua no espaço e no tempo à que se perdeu ou nunca se materializou, é apenas uma das muitas soluções possíveis (até que ponto? valeria a pena discutir esse problema). Entre as que certamente têm de ser excluídas está a invenção. Além de contraditório, seria, pelo que precede, absurdo. Entre outras coisas porque alguns dos mais célebres romancistas do século XIX falaram com desdém do recurso à invenção, atribuindo-o quando muito, com ironia, justamente aos historiadores. (GINZBURG, 2007b, p. 334).

Nesse sentido, a densidade literária do historiador é parte necessária de seu trabalho para lidar com as lacunas das fontes, levando-se em consideração uma diferença na gradação das certezas que o historiador apresente, a depender: das fontes diretamente relacionadas a seu objeto, das fontes marginalmente relacionadas e do levantamento da bibliografia já produzida a respeito tanto de seu objeto quanto de seu entorno.

No entanto, permanecer no objeto e no seu entorno não é uma abordagem ferramental suficiente para as pesquisas históricas. Os objetos investigados por Ginzburg e a necessidade de explorar aquelas "zonas opacas", em diálogo com sua formação familiar e acadêmica, implicou num necessário diálogo interdisciplinar para pensar as condições de produção de seu trabalho historiográfico. Por extensão, ele é válido para um objeto tão cheio de relações culturais como a educação.

\section{Diálogo interdisciplinar}

Ginzburg adota uma perspectiva que não considera a história como uma disciplina isolada das demais, em "exílio". Pelo contrário, sua obra está em constante diálogo com outras áreas do conhecimento. Em seus textos, fica evidente a relação da história com a psicologia, com a psicanálise, com a linguística, com a filologia, com a semiótica, com a morfologia e com a antropologia (v. GINZBURG, 1989, p. 7 e seguintes, pp. 99, 145 e 151; GINZBURG, 1991b, 
passim; GINZBURG, 2007b, p. 307; GINZBURG, 2010, p. 276). Campos específicos da história também são bastante explorados pelo autor: história das religiões e história da arte. Também podemos afirmá-lo em relação à ciência da literatura, à fotografia e ao folclore (v. GINZBURG, 1989, p. 143; GINZBURG, 1991b, passim; GINZBURG, 2001, p. 41; GINZBURG, 2007b, p. 231 e seguintes; GINZBURG, 2010, p. 276).

Essa aventura por outras áreas do conhecimento não significa a descaracterização delas em função da história, nem a diluição da história em outros campos disciplinares. Ginzburg, mesmo quando trata de um objeto específico de alguma área, o faz com o olhar do historiador e utiliza as contribuições dessas áreas de modo a compor esse olhar:

Certamente já se falou demais (sem se praticar, na maioria das vezes) em pesquisas interdisciplinares; mas é inegável que historiadores e historiadores da arte têm todos os motivos para trabalhar juntos, cada qual com seus instrumentos e competências próprios, a fim de chegar a uma compreensão mais aprofundada dos testemunhos figurativos. (GINZBURG, 2010, p. 20).

Ou como escreveu Philippe Ariès:

Eis por que as margens entre a história e as outras ciências humanas começam, enfim, a diminuir: acontecimento mais recente do que se poderia crer, depois de cinquenta anos de uma interdisciplinaridade proclamada, porém jamais vivida. (ARIÈS, 2011, p. 281) . $^{5}$

Quando convidado a tratar da interdisciplinaridade em uma publicação na área da história da arte, Ginzburg ponderou a respeito de seus usos ingênuos, em oposição ao perito em uma obra de arte. Ele lembra que a formação em uma disciplina significa acima de tudo "aprender quais questões, quais métodos, quais respostas devem ser consideradas inadmissíveis por seus praticantes", mas que isso, por vezes, pode esconder "uma aliança preguiçosa a tradições disciplinares" (GINZBURG, 1995, p. 534) ${ }^{6}$. No entanto, para Ginzburg, utilizar a interdisciplinaridade como uma forma de subversão de um programa intelectual desgastado torna-se um procedimento um tanto ingênuo.

Essa ingenuidade vem do fato que, por um lado, algumas abordagens interdisciplinares partem de pressupostos equivocados das áreas que são base da construção epistemológica. No caso da história da arte, por exemplo, Ginzburg mostra que alguns opositores do saber do perito acabam por utilizar saberes históricos de forma ingênua e positivista, como considerar que a existência de uma certidão de nascimento é a prova cabal da existência real de um sujeito com aquele nome. Além desse "positivismo ingênuo", está presente na atitude de um autor da história da arte citado por Ginzburg, um ceticismo em relação ao conhecimento histórico, que o associa com a ficção.

O historiador italiano mostra que essa atitude interdisciplinar ingênua está calcada numa oposição ao trabalho do perito, que seus opositores tendem a afirmar excessivamente disciplinar. Para se contrapor a essa posição, Ginzburg traz exemplos de como a perícia artística é profundamente interdisciplinar, como no caso de uma análise feita por um perito que envolveu a reunião de informações obtidas por "botânicos, arquivistas, paleógrafos, experts em marcas d'água, além dos historiadores da arte". Nesse caso, um bom perito possui uma "riqueza cognitiva" de tal monta e que, talvez, "implique maior, embora silenciosa, teoria do que a tão

\footnotetext{
${ }_{6}^{5} \mathrm{O}$ original foi publicado em 1978.

6 No original: "to learn which questions, which methods, which answers must be regarded as inadmissible by its practitioners."
} 
espalhada e supostamente teórica abordagem que trata trabalhos artísticos para ilustrar formulações gerais e preexistentes, tais como representações clássicas, modernidade etc.”. Propõe, então, o autor, considerar que certa "interdisciplinaridade por dentro" possa ser tão boa ou melhor do que uma "interdisciplinaridade de fora" que, no campo da história das artes pode ser uma atividade mais "segura, não desafiada pelos objetos com os quais ela lida e compreensivelmente muito mais popular do que sua alternativa" (GINZBURG, 1995, p. 536) ${ }^{7}$.

Esse diálogo interdisciplinar na obra de Ginzburg vem na esteira de uma tradição warburguiana de história da arte. Essa tradição passa por nomes como Bing, Wind, Saxl, Panofsky e Gombrich, sem deixar de lado Cassirer. O historiador italiano, assim como Frances Yates, Arnaldo Momigliano, Gershom Scholem passaram pelo Instituto Warburg em Londres. Como Ginzburg testemunhou num texto inserido em um dossiê dedicado a Warburg (GINZBURG, 2012), foi nas prateleiras da biblioteca do instituto que ele, nos anos 1960, encontrou um ensaio que iniciou as relações entre ele desenvolveu entre os Andarilhos do Bem e os Xamãs anos depois.

As ideias de Warburg e dos autores de tradição warburguiana estão voltadas para uma questão de método para compreender as relações entre testemunhos figurativos e história (GINZBURG, 1989, p. 41 e seguintes). De certo modo, a questão metodológica apontada nessa tradição foi desenvolvida por Ginzburg em sua pesquisa sobre a datação das obras de Piero de La Francesca (GINZBURG, 2010) e é bem detalhada nos usos que ele faz da noção de Pathosformeln em seu livro mais recente (GINZBURG, 2014).

Como escrevemos há alguns anos, comentando o exercício metodológico que o historiador italiano propôs para analisar as obras de Piero de La Francesca:

Essa interdisciplinaridade, já proposta por Ginzburg em obras como História noturna ou Mitos, emblemas e sinais (história e morfologia), bem como em Nenhuma ilha é uma ilha (história e literatura), tende, tradicionalmente, a se traduzir numa apregoada justaposição de resultados de áreas diversas. No entanto, o historiador italiano propõe fugir dessa prática pouco produtiva, visto que as divergências em relação a problemas concretos, como a questão da datação das obras de Piero, são mais frutíferas do que as convergências entre as áreas. É por meio das divergências que se pode "recolocar em discussão os instrumentos, as áreas e as linguagens de cada disciplina. A começar, sem dúvida, pela pesquisa histórica" (p. 21). (AGUIAR, 2021, p.69).

É nesse sentido que entendemos o diálogo interdisciplinar proposto pelo autor. Sem fugir das características e métodos de trabalho peculiares do historiador, ele pode utilizar contribuições de outras áreas para melhor compreender os objetos que está investigando. Aliás, estes objetos investigados são uma fonte permanente de provocações para o trabalho do historiador, tentado o tempo todo a diversificar seus instrumentos de investigação, alternando perícia (isto é erudição) com o diálogo com outras ciências. Foi o que fez o autor em sua obra, como vimos acima.

\footnotetext{
${ }^{7}$ Nos originais: "botanists, archivists, paleog-raphers, experts in watermarks, as well as art historians"; "This interplay of vetoes and compatibilities, doubts and suggestions, seems to be a distinctive feature of what I would call 'interdisciplinarity from within.' [...] Good connoisseurship, like Koreny's, has a cognitive richness which is unsuspected by its detractors as well as by some of its practitioners. It perhaps implies more, albeit silent, theory than the wide-spread, allegedly theoretical approach which treats works of art in order to illustrate general, preexisting formulations such as classical representation, modernity, and so forth. The latter we may call 'interdisciplinarity from without': this is a safer activity, unchallenged by the objects it deals with, and understandably far more popular than the alternative."
} 
No mesmo sentido, convém refutar a ideia da interdisciplinaridade como uma espécie de "panaceia metodológica". Ginzburg, quando se aventura pelas outras áreas do conhecimento, está solidamente ancorado na historiografia e nas ferramentas do ofício criadas pelos historiadores do passado.

\section{Tratamento documental}

Ginzburg utiliza-se à exaustão de documentação primária, que serve de ponto de partida para suas pesquisas históricas e propicia a discussão de diversas questões metodológicas especialmente relacionadas ao tratamento das fontes.

Uma delas diz respeito à presença do acaso na trajetória investigativa do historiador. Não é incomum que um documento produzido "por descuido" traga informações capazes de inverter toda a lógica de uma pesquisa: "Ao folhear um dos volumes manuscritos dos julgamentos [de uma seita de Friuli], deparei-me com uma sentença extremamente longa. Uma das acusações feitas a um réu era de que ele sustentava que o mundo tinha sua origem na putrefação" (GINZBURG, 1987, p. 9). No curso de uma pesquisa sobre bruxas, curandeiros e "andarilhos do bem", essa afirmação totalmente casual resultou no livro O queijo e os vermes. Semelhante experiência foi narrada quando o historiador italiano "estava trabalhando em um projeto avulso" na UCLA e um determinado tratado "cruzou [seu] caminho" (GINZBURG, 2007a). Ou ainda, quando Ginzburg comenta a "análise maravilhosa" que Federico Chabod fazia de um "documento esquecido, riscado, quase destruído, em cujo verso alguém, talvez um pequeno funcionário anônimo", havia escrito algumas frases sobre a predestinação, permitindo um olhar renovado sobre a história religiosa do Estado de Milão no século XVI e as primeiras reações à Reforma Protestante (GINZBURG, 1990).

O gesto do pesquisador (no caso, do historiador) é um gesto do acaso, arbitrário, por não ter sido obtido exclusivamente por um procedimento que pode ser mapeado de forma racional e objetiva do início até sua conclusão. Parte de nosso trabalho de pesquisa implica lidar com elementos que, à semelhança do sujeito histórico investigado n'O queijo e os vermes, é "um fragmento perdido, que nos alcançou por acaso, de um mundo obscuro, opaco, o qual só através de um gesto arbitrário podemos incorporar à nossa história." (GINZBURG, 1987, p. 26). O caráter fragmentário dos elementos da cultura do passado que buscamos compreender implica num "resíduo de indecifrabilidade", nos termos do autor, que precisa ser preservado. Resíduo que existe em toda pesquisa que busca compreender as pessoas, suas relações (e, em especial, as educativas).

Decorrente desse caráter fragmentário é o fato que, em muitos casos, as fontes que dispomos são duplamente indiretas, pois são escritas por pessoas ligadas à cultura dominante (hegemônica) mas preservam as vozes de pessoas das camadas subalternas, e são utilizadas para o estudo da cultura dessas camadas, como no caso de Ginzburg (1987). Cabe ao historiador decifrar a relação entre a cultura oral da população iletrada ou semiletrada em choque com a página impressa. Esse choque entre o livro e seu leitor, embebido numa cultura oral, fez com que o moleiro friuliano pudesse formular opiniões totalmente originais, para si mesmo, para seus concidadãos e para os juízes (GINZBURG, 1987, p. 89). Ou seja, as fontes inquisitoriais são registros escritos de testemunhos orais, o que provoca uma profunda mudança na forma com que essa documentação deve ser estudada e analisada.

Ainda sobre a cultura oral, a produção historiográfica de Ginzburg reafirma com frequência algo que, aparentemente óbvio, não pode ser negligenciado pelo pesquisador: "Uma cultura quase exclusivamente oral como a das classes subalternas da Europa pré-industrial tende a não deixar pistas, ou então deixar pistas distorcidas" (GINZBURG, 1987, p. 230). 
Ginzburg recomenda "Escovar a história a contrapelo", numa bela referência a Walter Benjamin, e "Aprender a ler os testemunhos às avessas, contra os testemunhos de quem os produziu" (GINZBURG, 2002, p. 43; GINZBURG, 2001, p. 217; GINZBURG, 2007b, p. 11).

Às pesquisas que buscam compreender períodos, fatos, personagens marcados pela escassez de documentos ou por fontes "duplamente indiretas", Ginzburg propõe um método indiciário, isto é: "Método interpretativo centrado sobre resíduos, sobre dados marginais, considerados reveladores" (GINZBURG, 1989, p. 145 e 149). Com ele, torna-se possível recuperar as vozes perdidas, distorcidas ou sufocadas do passado.

$\mathrm{Na}$ elaboração desse instrumental metodológico, o autor utiliza-se de Freud (sintomas), de Sherlock Holmes (indícios) e de Morelli (signos pictóricos) - isto é, do criador da psicanálise, de uma personagem literária e de um crítico de arte. Vale-se ainda do modelo da semiótica médica.

Para além do que já foi apontado nos comentadores marcados no início deste texto, especialmente em relação a um texto bastante referenciado como o ensaio Sinais, destacamos as duas epígrafes com as quais o autor inicia o texto. A primeira, "Deus está no particular", de Warburg, aponta para o jogo de escalas que o autor estabelecerá no texto e ao longo de sua obra (em especial nos livros Olhos de madeira e $O$ fio e os rastros). Esse jogo de escalas, de alternância entre o micro e o macro está marcado na discussão que Ginzburg faz sobre Siegfried Kracauer (1889-1966), escritor alemão, com uma obra conhecida no campo dos estudos sobre cinema, e que esteve no círculo de Adorno e Benjamin. Ginzburg o toma como um "interlocutor indispensável". No texto que dedica a Kracauer, o historiador italiano traz um trecho no qual o escritor alemão cita o diretor de cinema russo Vsevolod Illarionovich Pudovkin (1893-1953) descrevendo sua técnica de enquadramento:

Para ter uma ideia clara e precisa da demonstração, o observador deve [...] primeiramente trepar no telhado de uma casa para ver o pátio em sua totalidade e calcular seu tamanho; depois deve descer para olhar da janela do primeiro andar e ler os cartazes empunhados pelos manifestantes e, enfim, deve-se misturar com a multidão para ter uma ideia do aspecto externo dos participantes. (PUDOVKIN apud GINZBURG, 2007b, p. 246, grifo nosso).

Essa descrição é uma excelente imagem para, analogamente, descrever a narrativa histórica dos ensaios de Ginzburg. Em diversos momentos ele olha para o mesmo objeto com diferentes temporalidades e espacialidades. Como é este fenômeno histórico em outra região no mesmo período? Como o era na mesma região em outro período? Como ele se modificou num curto espaço de tempo? Como ele se modificou no espaço de tempo de séculos (ou milênios)? Especialmente no História Noturna, sua análise do Sabá das Bruxas faz diversos desses movimentos, mostrando, como apontamos acima, que Ginzburg não investiga os indícios para neles permanecer. Se "Deus" está naquilo que é particular, não é para ali permanecer, mas para compreender a totalidade que aquele particular permite acessar. Kracauer era alguém que "se definia como defensor das causas perdidas e associava ao close-up o tema de Davi e Golias, isto é, a convicção de que as forças mais significativas se manifestam no que é pequeno e insignificante [...]" (GINZBURG, 2007b, p. 248), e, com isso, o historiador italiano lembra da necessidade de ir ao particular.

A segunda epígrafe do ensaio sinais é do pintor americano da cena dadaísta Jasper Johns (nasc. 1930): "Um objeto que fala da perda, da destruição, do desaparecimento de objetos. Não fala de si. Fala de outros. Incluirá também a eles?". Trata-se de uma anotação de um artista plástico em momentos de criação, trazendo ideias sobre objetos que poderiam ser elaborados. Como epígrafe, Ginzburg traz uma referência à dúvida principal da leitura indiciária: um indício 
de um objeto permite chegar ao objeto $?^{8}$ Sua resposta, ao longo do texto, é positiva, sendo esta a marca metodológica de sua obra. No entanto, a caraterística de ser a leitura indiciária uma leitura indireta leva Ginzburg a destacar nossa relação de estrangeiro com as fontes.

$\mathrm{O}$ historiador é um estrangeiro no mundo das fontes, que deve penetrar as aparências exteriores e tentar compreender a realidade de dentro (GINZBURG, 2007b, p. 238.). O historiador é um "estrangeiro em relação ao mundo evocado pelas fontes" (GINZBURG, 2007b, p. 238) e esta condição só ocorre diante de uma atitude de dúvida, do nãoreconhecimento, de estranhamento. Este é um processo de busca pelo não-eu, pelo anômalo, pelo diferente que surge no "instante do não-reconhecimento" (GINZBURG, 2007b, p. 238). Consiste numa escrita pautada pelo exílio.

O não-reconhecimento não implica numa atitude positivista, de neutralidade, de isenção. Pelo contrário, como o próprio Ginzburg já apontou em outros momentos, em confronto com a postura cética, esse não-reconhecimento consiste em nossa implicação em todas as etapas da pesquisa. Nesse sentido, diante dessa nossa presença, podemos nos apresentar em nossa inteireza, narrativa e dialogicamente conosco, com nossas fontes/dados, com a bibliografia, considerando a escrita como um estado de exílio.

Assim, a ideia de distância como categoria de pesquisa trata-se, de fato, da vivência de um pensamento exilado. Ginzburg, ao comentar sua vivência como professor na UCLA e a distância cultural entre ele e seus alunos, reflete que:

Compreendi melhor algo que já pensava saber, isto é, que a familiaridade, ligada em última análise à pertença cultural, não pode ser um critério de relevância. "O mundo todo é nossa casa" não quer dizer que tudo seja igual; quer dizer que todos nos sentimos estrangeiros em relação a alguma coisa e a alguém. (GINZBURG, 2001, p. 11).

Nestes termos, uma pesquisa feita nesta postura de exílio, considerando o caráter fragmentário da leitura que fazemos das fontes, implica, ao olhar para os indícios, buscar entender o que há de estranho dentro do familiar. Além disso, o que nos une é justamente nossa leitura fragmentada do mundo, nosso exílio em relação ao outro, ao diferente e, portanto, a possibilidade dialógica de lidar com o outro é o que nos une. No campo da pesquisa, nosso primeiro outro é nosso objeto de pesquisa. E nosso segundo outro somos nós mesmos diante deste objeto. Ginzburg recomenda ao historiador de ofício valer-se permanentemente do estranhamento, como poderoso antídoto ao risco de banalizar a realidade e, simultaneamente, turvar a pesquisa (GINZBURG, 2001, p. 41).

Por fim, considerando essa relação exilada em relação às fontes, a obra de Gizburg acaba por propor, como regra geral no trabalho com os documentos, fazer uma leitura aprofundada deles, procurando superar o fato inegável de que, muitas vezes, quando existem em grande quantidade, os documentos são geralmente repetitivos (GINZBURG, 2007b, p. 293.). Convém então ao historiador desenvolver a já citada "arte de ler lentamente" e não ter medo de propor hipóteses arriscadas, mesclando-as com um permanente rigor no trato com as fontes (GINZBURG, 2007b, p. 302; GINZBURG, 2010, p. 250.). E não temer a ignorância - pelo contrário, valorizá-la como um momento de euforia e promissor para o desenvolvimento das pesquisas (GINZBURG, 2007b, p. 296.).

\footnotetext{
${ }^{8}$ Notemos que a citação de Ginzburg não traz a palavra final presente no caderno de notas de Johns logo após aqueles termos: "o dilúvio". O que este dilúvio pode significar é algo que ainda está fora de nossa compreensão, visto nosso pouco conhecimento da obra de Jasper Johns, mas não podemos deixar de levantar, como hipótese, que a ausência do dilúvio na citação epigráfica de Ginzburg é sua tentativa de se ater à possibilidade do método e não à perda no meio da destruição total.
} 


\section{Considerações finais}

Buscamos, neste texto, apontar ferramentas metodológicas que historiadores da educação interessados em uma leitura indiciária de suas fontes poderia utilizar, tomando a obra de Carlo Ginzburg, tanto no que diz respeito às questões teórico-metodológicas apontadas em seus textos quanto a um conjunto de elementos presentes no modo como ele escreve seus ensaios. Partimos de um diálogo com dois artigos que se propuseram, em tempos diferentes, a refletir sobre essas características em nosso campo. Do primeiro, compreendemos a centralidade da distância e do estranhamento para compreender as potencialidades da obra de Ginzburg para a história da educação, com especial destaque para o que aquelas potencialidades implicavam em relação a um objeto multifacetado como a educação. De lá, retomamos o caráter necessariamente interdisciplinar para o objeto "educação", o olhar "oblíquo" para a produção no campo da história da educação e a possibilidade de olhar fenômenos educacionais acessíveis apenas indiretamente.

Do segundo, compreendemos as marcas da história de vida e formação intelectual do historiador italiano em sua obra, em especial para a constituição do paradigma indiciário no encontro da leitura lenta da filologia, com a história de temas marginais, com o estudo do particular, com a produção dos linguistas de meados do século XX e com alguns dos escritos de Freud. Além disso, vislumbramos o estatuto da verdade e da prova, apontando esta como uma importante divergência entre o Paradigma Indiciário e a Análise do Discurso e entre esse paradigma e um conjunto de discussões "pós-modernas" ou "céticas".

$\mathrm{Na}$ sequência apontamos para a densidade literária apresentada pelo historiador italiano, compreendendo a necessidade de conhecermos textos clássicos produzidos pela humanidade, de utilizarmos fontes primárias e estarmos em diálogo com a produção dos outros historiadores que trabalha(ra)m com o mesmo objeto que estamos investigando. Essa necessidade de densidade literária é ainda mais relevante diante de um cenário no qual as lacunas das fontes implicam lidarmos com nossas certezas e dúvidas, apresentando termos que qualifiquem a gradação de nossas certezas.

Posteriormente, com o diálogo interdisciplinar, entendemos que sem fugir das características e métodos de trabalho peculiares da historiografia, o historiador pode utilizar contribuições de outras áreas para melhor compreender os objetos que está investigando, especialmente no que diz respeito às provocações que os diferentes olhares para o mesmo objeto podem nos trazer. Esse diálogo apontou para a necessidade de pensarmos nossos esforços metodológicos, especialmente para a história da educação, também buscando olhares de outras disciplinas.

Por fim, ao pensarmos no tratamento das fontes ressaltamos a presença do acaso na trajetória investigativa do historiador, o caráter fragmentário de nossa leitura de mundo e a necessidade de preservar um tanto da indecifrabilidade que caracteriza o humano e suas produções culturais. Essa preservação implica assumir uma postura de exilado em relação às fontes e em relação a nós mesmos, exílio esse construído com o estranhamento e a leitura lenta.

Como exercício de síntese, concluímos este artigo apontando para nossa atual compreensão de um método indiciário, que sistematizamos nos seguintes termos. Considerando o caráter fragmentário da realidade, remontamos uma realidade complexa, não experimentável diretamente, com indícios dispostos por nós, pesquisadores, de forma narrativa, em diálogo erudito com o entorno daqueles indícios. Por meio de uma leitura indireta dos indícios que recolhemos, construímos perguntas narrativas que possibilitem decifrá-los com um rigor flexível. Na alternância entre o micro e o macro, buscamos um conhecimento que possui um caráter de totalidade, partindo não apenas dos elementos recorrentes, mas das anomalias (visto que elas contêm a norma e a exceção). Num exercício de distância e estranhamento, nós, sujeitos implicados, aproximamo-nos do humano que é 
outro de nossa pesquisa, preservando o caráter de indecifrabilidade de tudo o que é humano, mas construindo uma narrativa que se propõe verdadeira dada a relação do real e de sua representação, que mesmo sendo altamente problemática, existe.

\section{Referências}

AGUIAR, Thiago Borges de. Jan Hus: cartas de um educador e seu legado imortal. São Paulo: Annablume, Fapesp, Consulado Geral da República Tcheca, 2012.

AGUIAR, Thiago Borges de. Investigando Piero, de Carlo Ginzburg (Resenha). Revista Brasileira de História da Educação, v. 12, n. 2[29], 2012, p. 267-280. Available at <http://periodicos.uem.br/ojs/index.php/rbhe/article/view/38794>. Last accessed May 8th 2020.

ARIÈS, Philippe. "A história das mentalidades". In: NOVAES, F. A. e SILVA, R. F. da (Ed.). Nova história em perspectiva. Vol. 1. São Paulo: Cosac Naify, 2011.

BURKE, Peter. "Miti, emblemi, spie: Morfologia e storia". The Journal of Modern History, Vol. 62, no. 1, Mar. 1990, p. 108-111. Available at: 〈www.jstor.org/stable/1898756>. Last accessed: May 8th 2020. DOI: https://doi.org/10.1086/243384.

DAVIS, Natalie Zemon. O retorno de Martin Guerre. Rio de Janeiro: Paz e Terra, 1987.

ESPADA LIMA, Henrique. A micro-história italiana: escalas, indícios e singularidades. Rio de Janeiro: Civilização Brasileira, 2006.

GINZBURG, Carlo. O queijo e os vermes: o cotidiano e as ideias de um moleiro perseguido pela Inquisição. Trad. Betania Amoroso. São Paulo: Companhia das Letras, 1987.

GINZBURG, Carlo. Os andarilhos do bem: feitiçaria e cultos agrários nos séculos XVI e XVII. Trad. Jônatas Batista Neto. São Paulo: Companhia das Letras, 1988.

GINZBURG, Carlo. Mitos, emblemas, sinais: morfologia e história. Trad. Federico Carotti. São Paulo: Companhia das Letras, 1989.

GINZBURG, Carlo. História e cultura: conversa com Carlo Ginzburg. Estudos Históricos. Rio de Janeiro, vol. 3, n. 6, 1990, p. 234-263.

GINZBURG, Carlo. A micro-história e outros ensaios. Trad. Antonio Narino. Rio de Janeiro: Bertrand Brasil, 1991a.

GINZBURG, Carlo. História noturna: decifrando o sabá. Trad. Nilson Moulin Louzada. São Paulo: Companhia das Letras, $1991 b$.

GINZBURG, Carlo. Inter/disciplinarity: vetoes and compatibilities. The Art Bulletin, Vol. 77, n.4, dez./1995, pp.534-536. Available at: 〈http://www.jstor.org/stable/3046135>. Last accessed: May 21st 2013. DOI: https://doi.org/10.2307/3046135.

GINZBURG, Carlo. Olhos de madeira: nove reflexões sobre a distância. Trad. Eduardo Brandão. São Paulo: Companhia das Letras, 2001. 
GINZBURG, Carlo. Relações de força: histórica, retórica, prova. Trad. Jônatas Batista Neto. São Paulo: Companhia das Letras, 2002.

GINZBURG, Carlo. Nenhuma ilha é uma ilha: quatro visões da literatura inglesa. Tard. Samuel Titan Jr. São Paulo: Companhia das Letras, 2004.

GINZBURG, Carlo. Latitudes, escravos e a Bíblia: um experimento em micro-história. ArtCultura, Uberlândia, v.9, n.15, p. 85-98, jul.-dec. 2007a.

GINZBURG, Carlo. O fio e os rastros: verdadeiro, falso, fictício. Trad. Rosa Freire d'Aguiar e Eduardo Brandão. São Paulo: Companhia das Letras, 2007b.

GINZBURG, Carlo. Investigando Piero: Batismo, o ciclo de Arezzo, a Flagelação de Urbino. Trad. Denise Bottmann. São Paulo: Cosac Naify, 2010.

GINZBURG, Carlo. Une machine à penser. Common Knowledge. v.18, n.1. 2012 Available at DOI: https://doi.org/10.1215/0961754X-1456890. Last accessed April 17th 2012.

GINZBURG, Carlo. Medo, reverência, terror: quatro ensaios de iconografia política. Trad. Joana Angelica D'Ávila Melo, Júlio Castanon Guimarães e Federico Carotti. São Paulo: Companhia das Letras, 2014.

LEONARDI, Paula e AGUIAR, Thiago Borges de. "As potencialidades para o uso da obra de Carlo Ginzburg na História da Educação". Revista Tempo e Espaços em Educação. Vol. 5, p. 107-123, jul./dec. 2010.

LEONARDI, Paula. Além dos espelhos: memórias, imagens e trabalhos de duas Congregações Católicas. São Paulo: Paulinas, 2010.

LEVI, Giovanni. O pequeno, o grande e o pequeno: Entrevista com Giovanni Levi. Rev. Bras. Hist., São Paulo, v.37, n.74, p.157-182, Jan./ 2017. Available at: DOI: https://doi.org/10.1590/1806-93472017v37n74-07. Last accessed March 3rd 2020.

PIRES, Francisco Murari. Indagações sobre um método acima de qualquer suspeita. História da Historiografia. v.6, n.13, dec./2013, p.24-44. Available at DOI: https://doi.org/10.15848/hh.v0i13.710. Last accessed May 8th 2020.

PERES, Fernando Antonio. João Penteado: o discreto transgressor de limites. São Paulo: Alameda, 2012.

SORGENTINI, Hernán. "Reflexión sobre la memoria y autorreflexión de la historia". Revista Brasileira de História, v.23, n.45. São Paulo, jul. 2003. DOI:https://doi.org/10.1590/S0102-01882003000100005.

VAINFAS, Ronaldo. Os protagonistas anônimos da História: micro-história. Rio de Janeiro: Campus, 2002. 